\title{
The Science Establishment Flunks
}

\section{Rustum Roy}

It has become fashionable--within the space of less than six months--for prominent leaders among scientists to be concerned with science education as distinct from research. On all sides we hear of the desperate straits of science education among the general American populace.

By and large, especially in relation to the developed nations, I believe that the U.S. citizenry and its leadership are indeed below the average elsewhere in a balanced understanding of science and technology and their impact on society. However, the main response of the science community to this situation is an appeal to government and to industry for more money. But non-scientist, politically astute observers detect a peculiar inconsistency in all this recently acquired concern for science education by this community.

How can it be, they reason, that the university science and engineering community should find itself in such desperate straits, when the Reagan administration has been relative kind to science budgets? For two or three decades, science was well funded indeed, the seeds of this problem were planted during the plush years of science's growth Surely money is not the only problem. Is it not in the values and priorities of the scientists themselves?

Have they shown a concern for the education in science of the general public? After all, the Public Understanding of Science program was judged by the science community itself for many years to be worth one-tenth of $1 \%$ of the budget of one agency (NSF) and zero in all others. Even the Reagan elimination of the National Science Foundation's science education directorate a mounted to only $6 \%$ to $7 \%$ of the total NSF budget.

\section{Do They Really Care?}

If, the critics argue, the science and engineering community felt so strongly about any of these aspects of science education, it could easily have shifted resources during the many fat years of science funding to establish the levels of activity that are their new targets.

In the 15 years that the total budget for academic research was growing steeply, the percentage of the NSF budget allocated to all science education had dropped from near $50 \%$ to nearer $5 \%$. For all those--in Congress and the agency--partly responsible for this change to rediscover education is indeed a turnabout. For them to make the charge that this was due to the "unimaginative" nature of NSF's science education program is ingenuous, to put it mildly.

I believe there is a most instructive lesson in our history of handling science education, and unless and until we in the science establishment radically change our own values (heal ourselves), we will be unfit and unable to mount a meaningful campaign to eradicate technological illiteracy and re-integrate science into the education of all Americans.

The lesson I draw from the facts about our neglect of science education on the general population is that the vast majority of the scientists who have made policy for this nation for the last two decades--as professors, deans, presidents, chairpersons or members of National Academy committees or the National Science Board--did not have any philosophical rationale for or against "science education" for the non-scientist. Most simply didn't think about it or care.

\section{Until we in the science establishment radically change} our own values, we will be unfit to mount a campaign to re-integrate science into the education of all Americans.

The wholeness of the educational fabric of a technologically advanced culture, from a citizen able to appreciate and criticize technology and science, to the support of esoteric astrophysics Ph.D.s, was not manifest in the science community's reductionist world view. "More money for research" was the single goal of most scientists and science-policy makers. And when it came to money for science education, even of scientists, it was a very poor relation indeed compared to more money for research.

Therefore, it is my opinion that giving a little (\$100 million) more money for science education of the general public cannot possibly do any good if it is given through this same community. Its gut-level attitudes simply cannot change that fast. Perhaps a Solomonic test would be to ask NSF, NIH and the rest, in a zero-based budget exercise, to see what percentage they would be willing to give up out of research budgets for science education. The government should then match that amount with additional money for science education within that agency. This would provide a mind-focusing exercise and a cathartic selfhealing via repentance for both the science community and the nation.

To improve a very bad situation, I believe the executive or the Congress can move fast via a different program in a different agency, and one which has an excellent antecedent. I note first that it is genuinely in line with the concept of the new (or old) federalism. A new initiative on nationwide technological literacy could be modeled on former Assistant Secretary of Commerce Herbert Holloman's invention: the State Technical Services Act (STSA).

I propose that an analogous State Science Education Act (SSEA) be enacted with two components. One will provide (on the basis of a formula incorporating the number of school students, high-school graduates, two-year technical graduates and college degrees) a grant to be matched on a three-federal-dollars to one-state-dollar basis, for state-run programs designed to eradicate technological illiteracy and upgrade science education for the non-specialist at every level.

Volunteer Contributions

The second part, somewhat along the lines of the STSA, would provide federal grants with an even higher matching ratio to consortia, regional associations and national groups, for programs agreed upon as being of value to any group of states.

Such programs might involve, for example, development of course content and teaching materials for print or TV. Using block-funding mechanisms, perhaps a five-person federal bureaucracy could run the whole office out of the Commerce Department. Moreover, by having 50 states run the SSEA program, we would move the action away from the research-oriented Washington bureaucracy, toward the level of government that in any case has the responsibility for much of science and general education.

Due to the shortage of science teachers nationwide, the only mechanism for rapid improvement of the national posture is through the volunteer route. The vast majority of our school districts could find in local industry, community college or university, scientists and engineers who would give up several hours a week to teach science at the local school and help in local cable TV, newspaper or other community programs. Such volunteer contributions would count as matching money in kind, to qualify for extra state grants. Moreover, this scheme would not disturb the basic structure of the existing science teachers' employment, while permitting a gradual expansion of the personnel capable of explaining and interpreting technology in the context of society.

The bottom line comes down to this: In an era of fixed intellectual and financial resources, can the high science research community be entrusted with the science education of the American people?

This essay originally appeared in The Wall Street Journal of Oct. 8. Roy, an MRS councillor. is a science fellow of the Brookings Institution, as well as director of Penn State's materials research laboratory. 